\title{
Cyclooxygenase in biology and disease
}

\author{
RAYMOND N. DUBOIS, ${ }^{*}, 1$ STEVEN B. ABRAMSON, ${ }^{\dagger}$ LESLIE CROFFORD, ${ }^{\ddagger}$ \\ RAJNISH A. GUPTA,* LEE S. SIMON, $\$$ LEO B. A. VAN DE PUTTE, PETER E. LIPSKY \\ *Departments of Medicine/GI \& Cell Biology, Vanderbilt University Medical Center, Nashville, \\ Tennessee 37232, USA; ${ }^{\dagger}$ Department of Rheumatology, New York University School of Medicine, \\ Hospital for Joint Diseases, New York, New York 10003, USA; ${ }^{\ddagger}$ Division of Rheumatology, University of \\ Michigan Medical Center, Ann Arbor, MI 48109-0680; ${ }^{\S}$ Division of Rheumatology, Harvard Medical \\ School, Beth Israel Deaconness Medical Center, Boston, Massachusetts 02215, USA; "Division of \\ Rheumatology, University Hospital Nijmegen. 6500 HB Nijmegen, The Netherlands; "Rheumatic \\ Diseases Division, Harold C. Simmons Arthritis Research Center, The University of Texas \\ Southwestern Medical Center at Dallas, Texas 75235-8884, USA
}

\begin{abstract}
Cyclooxygenase (COX), the key enzyme required for the conversion of arachidonic acid to prostaglandins was first identified over 20 years ago. Drugs, like aspirin, that inhibit cyclooxygenase activity have been available to the public for about 100 years. In the past decade, however, more progress has been made in understanding the role of cyclooxygenase enzymes in biology and disease than at any other time in history. Two cyclooxygenase isoforms have been identified and are referred to as COX-1 and COX-2. Under many circumstances the COX-1 enzyme is produced constitutively (i.e., gastric mucosa) whereas COX-2 is inducible (i.e., sites of inflammation). Here, we summarize the current understanding of the role of cyclooxygenase-1 and - 2 in different physiological situations and disease processes ranging from inflammation to cancer. We have attempted to include all of the most relevant material in the field, but due to the rapid progress in this area of research we apologize that certain recent findings may have been left out.-DuBois, R. N., Abramson, S. B., Crofford, L., Gupta, R. A., Simon, L. S., van de Putte, L. B. A., Lipsky, P. E. Cyclooxygenase in biology and disease. FASEB J. 12, 1063-1073 (1998)
\end{abstract}

Key Words: Prostaglandins · Inflammation

In 1893, German chemist Felix Hoffman, motivated by concern for his father's severe rheumatoid arthritis, set into motion a commercial process for his employer, the Bayer Company, to produce a molecule with analgesic activity called acetylsalicylic acid or aspirin. What evolved from this historic event was a class of drugs, nonsteroidal antiinflammatory drugs (NSAIDs), that are still among the most widely used therapeutic agents known to humankind 100 years later. In one year in the U.S. alone, approximately 50 million people, spending some 5-10 billion dollars, consume NSAIDs for the treatment of a wide spectrum of pathophysiological conditions. These include prophylaxis against cardiovascular disease, re- lief of the discomfort associated with minor injuries and headaches, and alleviation of the severe pain caused by a variety of inflammatory and degenerative joint diseases.

Despite the wide use of NSAIDs over the last century, their mechanism of action was not fully appreciated until 1971, when Vane published his seminal observations proposing that the ability of NSAIDs to suppress inflammation rests primarily on their ability to inhibit the cyclooxygenase (COX) enzyme (1). This would limit the production of proinflammatory prostaglandins (PGs) at a site of injury. Given this, NSAIDs have been used by scientists for the last 25 years to dissect the critical role that both the COX enzyme and the eicosanoids derived from this pathway have in normal and abnormal physiologic states.

The chemistry of the eicosanoid biosynthetic pathway is well known. Prostaglandins are formed by the oxidative cyclization of the central 5 carbons within 20 carbon polyunsaturated fatty acids (2). The key regulatory enzyme of this pathway is COX (COX) (PGH synthase), which catalyzes the conversion of arachidonic acid (or other 20 carbon fatty acids) to prostaglandin (PG) $\mathrm{G}_{2}$ and $\mathrm{PGH}_{2}$. $\mathrm{PGH}_{2}$ is subsequently converted to a variety of eicosanoids that include $\mathrm{PGE}_{2}, \mathrm{PGD}_{2}, \mathrm{PGF}_{2 \alpha}, \mathrm{PGI}_{2}$, and thromboxane (TX) $\mathrm{A}_{2}$ (Fig. 1). The array of PGs produced varies depending on the downstream enzymatic machinery present in a particular cell type. For example, endothelial cells primarily produce $\mathrm{PGI}_{2}$, whereas platelets mainly produce $\mathrm{TXA}_{2}$ (for general review of this topic, see refs 3,4). All NSAIDs in clinical use have been shown to inhibit COX, leading to a marked decrease in PG synthesis (5).

\footnotetext{
${ }^{1}$ Correspondence: Department of Medicine/GI; MCN C2104, Vanderbilt University Medical Center, Nashville, TN 37232-2279, USA. E-mail: duboisrn@ctrvax.vanderbilt.edu

${ }^{2}$ Abbreviations: NSAIDs, nonsteroidal antiinflammatory drugs; COX, cyclooxygenase; PGs, proinflammatory prostaglandins; TX, thromboxane
} 


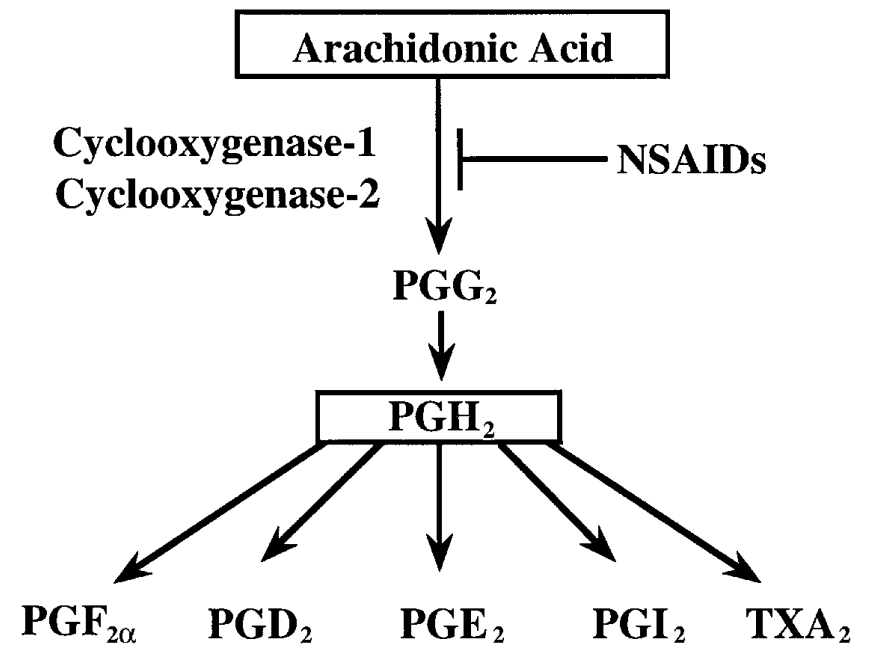

Figure 1. Schematic diagram for the conversion of arachidonic acid to prostaglandins and other eicosanoids by the cyclooxygenase enzymes.

Prostaglandins are found in animals as primitive as the coelenterates and are present in a wide variety of human tissues (2). PGs not only play a central role in inflammation, but also regulate other critical physiological responses. In humans, prostaglandins are involved in diverse functions, including blood clotting, ovulation, initiation of labor, bone metabolism, nerve growth and development, wound healing, kidney function, blood vessel tone, and immune responses. In contrast to hormones such as cortisone or thyroxin, which have broad systemic effects despite being released from a single site in the body, PGs are synthesized in a broad range of tissue types and serve as autocrine or paracrine mediators to signal changes within the immediate environment (Fig. 2). Two classes of prostaglandin receptors exist to transduce signals upon binding of ligand, the G-coupled cytoplasmic receptor class (i.e., EP1-4 for $\mathrm{PGE}_{2}$ ) and the nuclear PPAR receptor class (i.e., PPAR $\alpha$, PPAR $\gamma$, PPAR $\delta$ ), which acts directly as a transcription factor upon ligand binding (7).

Given the broad role PGs play in normal human physiology, it is not surprising that systemic suppression of PG synthesis through inhibition of COX can lead to unwanted side effects. In particular, individuals taking NSAIDs for even short periods of time can experience gastrointestinal and renal side effects $(8$, 9) in addition to effects on other physiological systems. As many as $25 \%$ of individuals using NSAIDs experience some type of side effect, and as many as $5 \%$ develop serious health consequences.

The different effects of PGs can be explained by considering their varied chemistry, the diversity of PG receptors, and modulation of PG synthesis by local upstream and downstream effects. This review will focus on the role of COX enzymes (COX-1 and COX2 ) on the biology of many different organ systems.
Since NSAIDs clearly have proven efficacy in treating human disease, while having well-documented deleterious side effects, an intense amount of research over the last 5-10 years has been devoted to distinguishing the role of each type of COX isoform in these two processes. One major goal of this work is the design of an antiinflammatory drug with a wider therapeutic window.

Investigators studying cell growth signaling pathways identified a unique, inducible gene product related to the known COX sequence (see ref 3 for review). Concurrently, investigators looking at PG production in response to cytokines and other inflammatory factors noted increases in COX activity that could only be accounted for by increased expression of another cyclooxygenase (10). Both immunoprecipitation of this COX variant with an antiCOX antibody, as well as the production of an antibody that precipitated only the COX-2 isoform, allowed for the identification of two different COX isoforms. It was subsequently determined that the COX-1 and COX-2 proteins are derived from distinct genes that diverged well before birds and mammals (11).

Taken together, these early studies revealed that while both enzymes carry out essentially the same catalytic reaction and have similar primary protein structures (12), many of the inflammatory, inducible effects of COX appeared to be mediated by the newly discovered COX-2, while many of the 'housekeeping' effects of COX appear to be mediated by COX-1. This functional role for each isoform is consistent with their tissue expression patterns: nearly all normal tissues were found to express COX-1 with low to undetectable levels of COX-2. However, COX-2 is constitutively expressed in the brain and kidney of rodents. Other differences between COX-1 and

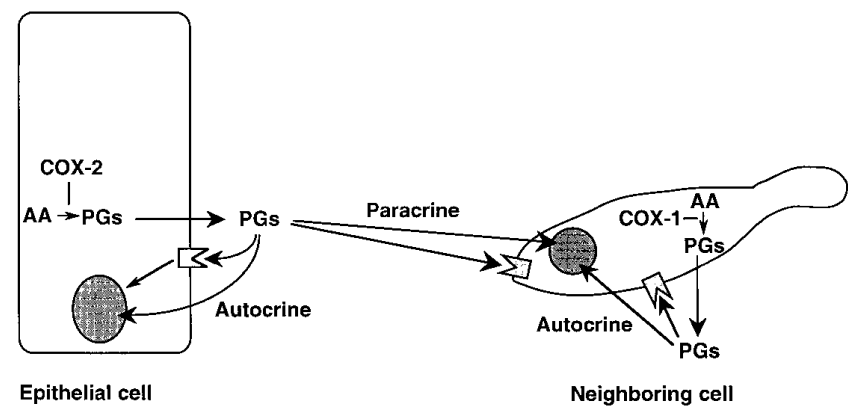

Figure 2. Schematic diagram of potential mechanisms involved in the cyclooxygenase-mediated regulation via paracrine and autocrine pathways. Arachidonic acid, AA; prostaglandins, PGs; receptor-mediated pathways are indicated. Prostaglandins can act via G-coupled cytoplasmic membrane receptors or nuclear peroxisome proliferator activated receptors (PPARs). Obviously, to activate PPARs, prostaglandins would not necessarily have to exit the cell and then reenter; they could transit directly from the cytoplasm to the nucleus. 
COX-2 include differences in utilization of arachidonic acid substrate pools as well as in mRNA stability $(13,14)$.

The regions regulating gene expression of COX-1 and COX-2 show little similarity. For example, the promoter and enhancer regions regulating COX-2 contain a variety of response elements that have been shown to explain, at least in part, its inducibility by hormones, growth factors, phorbol esters, cAMP, inflammatory factors, and cytokines. Much less is known about the elements involved in regulating COX-1 gene expression, although studies have reported induction of COX-1 in some circumstances involving differentiation of macrophages (16-19).

COX-1 and COX-2 also show major differences in mRNA splicing, stability, and translational efficiency. Regulation of COX-2 at the mRNA level appears to be an important mechanism by which some physiological mediators, notably the corticosteroids (consistent with their immunosuppresive properties, downregulate COX-2 expression), act to regulate PG production.

Another major difference between COX-1 and COX-2 appears to be in their ability to use different substrate pools. For example, in both fibroblasts and immune cells, COX-2 was able to utilize endogenous arachidonic acid whereas COX-1 was not. In these systems, COX-1 requires exogenous substrate. Soluble $\mathrm{PLA}_{2}$ can produce an alternative source of substrate for COX-1, and Herschman (3) has suggested that in some tissues the release of $\mathrm{sPA}_{2}$ from neighboring cells might provide the primary regulation of COX-1 activity. If this is the case, then the regulatory elements responsible for increasing PG production would not involve the COX-1 gene, but rather the $\mathrm{sPLA}_{2}$ gene.

In summary, the COX-1 and COX-2 genes are regulated by two independent and quite different systems even though the enzymatic reaction they catalyze is identical. How these systems function in health and disease, how they are regulated, and how they interact will be addressed in the remainder of this review.

\section{COX-1}

As noted above, COX-1 has been localized in nearly all tissues under basal conditions (20). From this type of tissue expression pattern, one would expect that COX-1's major function is to provide PG precursors for homeostatic regulation. One important site of COX-1 function is the blood platelet, where the enzyme is responsible for providing precursors for thromboxane synthesis (21). Teleologically this makes sense, since platelets, which do not have nuclei, cannot produce an inducible enzyme in response to activating conditions. Rather, platelets carry a supply of COX-1. In the presence of an NSAID like aspirin, platelets are prevented from generating thromboxane during activation and fail to complete successful aggregation, inhibiting their thrombogenic potential. In the adjacent vascular endothelium, PGs play a different role. The release of eicosanoids by activated platelets is thought to provide both a substrate and stimulus for the generation of prostacyclin $\left(\mathrm{PGI}_{2}\right)$ by the endothelium. This compound stimulates vasodilatation, counteracting the vasoconstrictor, thromboxane.

COX-1 appears to function in two other physiological systems leading to vasodilatation in the presence of contractile conditions. In both the kidney and the stomach, normal physiological stimuli are associated with dramatic changes in blood flow. During times of lowered blood volume, the kidney releases angiotensin and other factors to maintain blood pressure by systemic vasoconstriction (22). At the same time, angiotensin provokes PG synthesis in the kidney. COX-1 is expressed in the vasculature, glomeruli, and collecting ducts of the kidney, and it appears to be important in producing the vasodilating PGs, which maintain renal plasma flow and glomerular filtration rate during conditions of systemic vasoconstriction. In the presence of NSAIDs, this protective response fails, leading to renal ischemia and damage in susceptible individuals (23). Similarly, in the gastric antrum, NSAID use leads to ischemia followed by mucosal damage and ulceration (24). The enzyme blocked by NSAIDs is thought to be COX-1 (25) that produces PGs, which alter blood flow in the microcirculation of the gastric mucosa.

So COX-1 acts in a variety of settings to produce homeostatic or maintenance levels of PGs. In some cases, induction of $\mathrm{PLA}_{2}$ is responsible for increased PG synthesis. In others, COX-1 levels are modulated (i.e., macrophages stimulated to differentiate). It is not yet clear whether all cells and tissues with COX1 rely on exogenous supplies of substrate, but this situation would allow for a variety of cooperative mechanisms tying COX-1 activity to neighboring physiological requirements.

\section{COX-2}

One of the first studies conducted after the discovery of two isoforms of COX was a screen of existing NSAIDs for those that had differential effects on inhibition of COX-1 vs. COX-2, and some were found to have a 20- to 70-fold selective preference $(26,27)$. As a result, studies were done using differential inhibition of COX-1 or COX-2 activities to sort out the relative contributions of these isoforms under a variety of experimental conditions. While initial studies upheld the concept that COX-2 is mainly an inflammatory, inducible enzyme, more recent studies are 
beginning to reveal additional functions (15). We will now turn our attention to the various organ systems and disease states where COX-2 appears to have functional significance.

\section{Renal function}

Prostaglandins are known to serve as important physiologic modulators of vascular tone and sodium and water homeostasis in the mammalian kidney, including modulation of glomerular hemodynamics, tubular reabsorption of sodium and water, and regulation of renin secretion. While COX-1 has long been recognized to be involved in normal kidney function, COX2 is now seen to have a distinct role. Localization studies have found COX-2 in both the macula densa of the rat kidney (28) and the interstitial cells of the medulla (29). The macula densa plays an important role in mediating the interaction among glomerular filtration, proximal reabsorption, and regulation of renin release (30), which in turn is responsible for sodium balance and fluid volume. Although, $\mathrm{PGE}_{2}$ has been reported to inhibit chloride reabsorption in the ascending limb of Henle (31), chronic sodium deprivation was found to increase COX-2 levels in the region of the macula densa, and COX-2-generated prostanoids may be important mediators of renin production and tubuloglomerular feedback. The details of interactions between the COX-1 and COX-2 mediated systems in the kidney are not clear. Mapping of PG receptors in the kidney (6) does show differential locations of receptors specific for different PGs, indicating that differential synthesis of specific types of prostaglandins may be responsible for separating the effects of COX-1 and COX-2.

In addition to the multiple roles played by PGs in the adult kidney, COX-2 null mice show severe disruption of kidney development $(32,33)$. The localization and level of COX-2 expression in the human kidney is currently unknown, but this information will be essential in evaluating the role of COX-2 in human kidney function. NSAIDs are known to have multiple effects on kidney function, and specific COX-2 inhibitors should be useful in dissecting the role of PGs generated from the COX-2 pathway in normal renal physiology.

\section{Nerve and brain function}

COX-2 seems to have some role in regulating brain function. PGs have long been known as mediators of fever, of inflammatory reactions in neural tissue, and, more recently, of brain function. The recognition that each of these processes involves induction of $\mathrm{PG}$ synthesis has led to an appreciation of the role COX2 plays in the PG-mediated functions. While NSAIDs are commonly used to control fever, the actual mechanism of fever induction has only recently been de- scribed. Intraperitoneal injection with lipopolysaccharide (LPS) causes a marked fever response in rats. In an elegant dissection of molecular and tissue interactions, Cao and colleagues have shown how COX2 induction in brain endothelial cells temporally parallels the fever response $(34,35)$. This leads to the synthesis of PGs, which then act on temperature-sensing neurons in the preoptic area. In turn, COX-2 inhibition by an isoform-specific NSAID can effectively block fever (36). Communication between local inflammatory sites and the brain endothelium is mediated by cytokines such as IL-1, which can directly induce COX-2 expression in these cells (37). These investigators have also shown induction of COX-2 expression in other parts of the brain, but these areas are not directly associated with the fever pathway.

A separate inflammatory pathway is one mediated by microglial cells, a type of tissue-specific macrophage that lies dormant until needed for defense or tissue remodeling (38). While known as a source of PGs during inflammatory states, the microglial cell does not show induction of COX-2 in response to cytokines, in strong contrast with other inflammatory cells. Instead, the microglial COX-2 response is limited to direct LPS exposure, an event that would only occur by direct bacterial infection of the brain. Thus, the microglial defensive response is segregated from systemic inflammation by its limited repertoire of inducers.

This segregation of the brain from systemic inflammatory inducers is important because COX-2 also plays a central role in neural development and adaptation. During earlier stages of brain development, neural genes and proteins are developmentally induced and play a major role in the maturation process. During later stages of maturation, however, environmental influences, as represented by neural responses and synaptic activity, play an increasingly important role in determining brain structure. It is in these final stages of development and brain modeling that COX-2 becomes active in a manner that coincides with the imprinting of environmental influences (39).

COX-2 remains an important modulator of neural response throughout adult life. COX-2 levels increase dramatically after seizures and N-methyl-D aspartatemediated activity (40). The sites of induction are the postsynaptic dendritic arborizations (41) of specific excitatory neurons located in the major processing centers of the brain. The actual role of COX-2 and PGs in these sites is not yet understood, but associations between COX-2 induction and neural degeneration after glutamate stimulation (42), seizures, and spreading depression waves (43) suggest that COX-2 may play more of a role in the selective loss of neural connections than in their formation.

\section{Maintenance of gastrointestinal integrity}

The intestinal epithelium is a tissue that undergoes constant regeneration in response to both insult and 
normal use. The use of NSAIDs causes a variety of problems in the gastrointestinal tract (44) including irritation and ulceration of the stomach lining (45). Radiation exposure leads to intestinal epithelial cell death, leaving crypt cells to regenerate the population. In animal studies, COX-2 is not induced after exposure to radiation, and its presence is not essential for crypt cell survival (46). Under these circumstances, COX-1 appears to play a major role, as it does in the stomach, in maintaining proper glandular architecture. For example, indomethacin, which effectively inhibits COX-1, suppressed crypt survival and $\mathrm{PGE}_{2}$ production in intestine after radiation damage. Gastrointestinal epithelium is also the target of numerous infectious and parasitic organisms. In response to infection or invasion, COX-2 expression is induced in epithelial cells (47), which leads to increased PG production. The PGs then stimulate chloride and fluid secretion from the mucosa, which flushes bacteria from the intestine. In addition, COX2 is expressed during inflammation and wound healing, and in animal models, treatment with COX-2 inhibitors can exacerbate inflammation and inhibit healing. Nevertheless, COX-2 selective inhibitors appear to be associated with less gastrointestinal damage than conventional NSAIDs (48). Clinical trials evaluating compounds that are highly selective for COX-2 are under way, and preliminary results indicate a paucity of gastrointestinal side effects.

Many of the diverse roles of PGs in the intestine have been revealed by studying the effects of indomethacin or other NSAIDs. For example, Giannella et al. (49) found that indomethacin could effectively suppress the rapid intestinal fluid secretion accompanying Salmonella infection of rhesus monkeys. More recently, Eckmann et al. (47) have dissected this effect and shown that Salmonella infection of cultured intestinal epithelial cells gives rise to a rapid induction of COX-2, an associated rise in PGs, and an acceleration in chloride secretion that can be blocked by an anti-PGE antibody. With the response of infected cells, uninfected cells also acquired a state of increased fluid secretion, demonstrating the paracrine nature of the PG response. This model shows the essential features of the PG response: upregulation of COX and PG synthesis, physiological adaptation to infection, and coordination of a protective response.

\section{Ovarian and uterine function}

One of the earliest noted sites of PG accumulation was amniotic fluid (50), and one of the first known biological responses to a prostaglandin was the rhythmic contraction of the uterine myometrium. These associations with pregnancy and labor led to the recognition of PGs as a major effector in induction of labor. Indeed, Zuckerman et al. (51) administered indomethacin as a treatment for premature labor with dramatic results. Out of 50 women, $80 \%$ experienced cessation of uterine contractions. However, five infants from the treated mothers died because of premature closure of the ductus arteriosus, a circulatory shunt in the fetus that allows the output of the left ventricle to bypass the fetal lungs, which is maintained by PGs (52). Prenatal indomethacin is sufficient to block PG production leading to premature duct closure and disruption of fetal circulation (52).

Ovulation, the process by which oocytes are released from the preovulatory follicle in the ovary is accompanied by induction of prostaglandin synthesis as a consequence of the LH surge. This marked response led to the first observation of COX-2 induction during a normal physiological event (53). One of many molecular events associated with ovulation (54), the induction of COX-2 is necessary for the successful rupture of the follicle, probably mediating directly the generation or activation of proteolytic enzymes necessary for this process (55). Induction of COX-2 can be modulated by the gonadotropins LH and FSH, and by TGF- $\alpha$, IL-1, or other cellular signaling pathways (58).

After fertilization, COX-2 again plays a role, this time during implantation of the embryo in the uterine endometrium. During the pre-implantation period, uterine COX-1 (59) and the $\mathrm{PGE}_{2}$ receptors, EP1, EP3, and EP4 (60), may modulate preparation of the uterus for interaction with the embryo, and COX-2 (59) and the EP2 receptor (61) appear to mediate the embryo-uterine interactions during implantation. COX-2 null mice show multiple failures in reproductive function, including ovulation, fertilization, implantation, and decidualization, underscoring the multiple roles of PGs during these processes (62). Finally, at the completion of pregnancy, PGs again act in the ovary and uterus to help mediate the delivery process. As mentioned above, PGs have long been known to stimulate uterine contraction. In mice, the production of $\mathrm{PGF}_{2 \alpha}$ by the fetal and/or uterine tissues signals the ovary to induce luteolysis (63), leading to a decline in maternal progesterone and the induction of oxytocin receptors in the myometrium. This induction in turn increases the myometrial response to oxytocin and brings on parturition.

\section{Bone}

The role of PGs in bone metabolism is not only complex, but also is apparently contradictory. For example, while PGs were initially characterized by stimulating bone resorption in culture, human and animal responses to PGs often include stimulation of bone formation (64). Collagen synthesis by osteoblasts can be both stimulated (65) or inhibited by PGs. Mechanical stress on bone cells leads to an increase in 
PG synthesis, suggesting that immobilization would be characterized by low PG levels (66). Nevertheless, immobilization is associated with PG-mediated bone loss, an effect that is slowed by NSAIDs.

PGs act on the modeling of bone in several ways. They stimulate the differentiation of precursors of both the bone resorbing cells (osteoclasts) and the bone-forming cells (osteoblasts), they stimulate bone resorption in vitro, and they stimulate bone growth when given exogenously in vivo (67). While little is known of how PG synthesis effects the balance between bone loss and formation, COX-2 induction in osteoblasts is reported to be essential to the acute stress response in a bone remodeling system (68). Bone loss is associated with inflammation in periodontal disease (69) and NSAIDs can slow this process (70). Cytokines associated with inflammation, including IL-1 $\beta$ and IL-6 (72), have been found to induce both COX-2 and increase PG production when added to bone marrow cells in culture. In response, osteoclasts are induced to differentiate from their stem cell precursors. Osteoblasts and marrow stromal cells are the site of COX-2 induction and are further activated by the increased production of PGs. Other cytokines, for example IL-4 and IL-13, appear to suppress this response (73). Other inducers of COX-2 include parathyroid hormone (74), an important regulator of calcium metabolism, vibrational forces (75) and pulsating fluid flow (66), both of which are thought to model physical forces associated with mechanical stress on bone. Thus, it appears that stimuli that lead to both breakdown and building of bone use the same basic pathways to activate the bone remodeling system and that in bone PGs are responsible for ensuring that this resorption and formation occur coordinately, preventing an imbalance between these two processes.

\section{Inflammation and arthritis}

Although the importance of COX activity in the production of PGs has been known since 1967 (76), the inducibility of this activity and the central role of this induction in the amplification of inflammation have been fully appreciated only recently (77). Evidence provided by animal models of inflammatory arthritis strongly suggests that increased expression of COX2 is responsible for increased PG production seen in inflamed joint tissues (78). COX-2 induction has been observed in both human osteoarthritis-affected cartilage (79) as well as in synovial tissue taken from patients afflicted with rheumatoid arthritis (80). Cell culture experiments utilizing primary cells derived from human synovial tissue or cell types (e.g., monocytes) important in inflammatory processes have been critical to an understanding of factors involved in modulating this induction. The pro-inflammatory agents IL-1, TNF- $\alpha$, and LPS, as well as the growth factors TGF- $\beta$, EGF, PDGF, and FGF, have all been shown to induce COX-2 expression in this system. On the other hand, the antiinflammatory cytokines IL-4 and IL-13, as well as the immunosuppresive glucocorticoids, were shown to decrease COX-2 levels (20).

Although the synovial tissues of patients with osteoarthritis express lesser amounts of COX-2, primary explant cultures of human osteoarthritis-affected cartilage spontaneously express large amounts of COX-2 and PGs (79). Nitric oxide, another important inflammatory modulator, has been shown to regulate PG production in osteoarthritic cartilage, though not in synovial cells. Whether this modulation attenuates or enhances COX activity remains controversial $(79,81)$.

The rapid expansion of knowledge about the role of COX-2 in inflammation led to drug screens attempting to identify antiinflammatory agents selective for COX-2 as well as to the rational design of highly selective COX-2 inhibitors (82). The availability of these COX-2 inhibitors has now allowed for the design of studies that could directly determine the importance of COX-2 in inflammatory disease. COX2 is reported to be central to the inflammatory process and COX-2 inhibition is sufficient to achieve the same therapeutic endpoints found with less specific inhibitors that also target COX-1(83).

\section{Pain}

Local tissue injury and inflammatory diseases like osteoarthritis are associated with increased PGs, and pain receptors are known to be sensitized to lower levels of stimulus by PGs (84). Thus, the action of COX at the site of injury or inflammation is hyperalgesic, and the pain-relieving action of NSAIDs at the local site is easily explained by this mechanism. In addition, PGs are thought to act in the spinal cord to facilitate the transmission of pain responses, though there is little known about how they might do this (85). NSAIDs can also act at these central sites (86-88).

COX-2 is induced in both local and central sites (89), and the question of whether COX-2 mediates pain reception or transmission is being investigated, primarily through the use of COX-2 specific NSAIDs. Intrathecal injection of both the COX-2 specific inhibitor NS-398 and the nonspecific NSAID indomethacin suppressed a formalin-mediated pain response (which measures a central response), but neither suppressed a high temperature-induced pain response (i.e., a local response) (85). In contrast, systematically administered meloxicam, an NSAID more specific for COX-2 than COX-1, suppressed the inflammatory pain response locally (90) without affecting central pain transmission. In neither of these studies was the drug introduced into both sites to allow an internal comparison, but together they show 
that COX-2 can act both locally and centrally to mediate pain. In fact, the COX-2 specific inhibitor Celecoxib was shown in short-term human studies to effectively suppress the pain associated with dental work, osteoarthritis, or rheumatoid arthritis without causing any significant gastroduodenal lesions $(91,92)$.

\section{Alzheimer's Disease}

NSAID use reduces risk for Alzheimer's Disease (AD), with users of these agents having as little as one half the risk of acquiring $\mathrm{AD}$ as those not taking NSAIDs (93-95). A few studies that attempt to identify a role for COX in the etiology of $\mathrm{AD}$ have followed up this observation. Evidence of inflammatory mediators and activated microglia at the sites of $\mathrm{AD}$ lesions offer the possibility that chronic inflammation could directly cause neural damage, but other evidence contradicts this as the central mechanism (96-97). Tocco et al. (42) have described the appearance during rat brain development of COX-2 induction in response to kainic acid-induced seizures. Notably, the neurons that express COX-2 also show evidence of apoptosis. These links between high NMDA-mediated neural activity, COX-2 induction, and cell death, may prove to be causal in AD. Breitner (97) has pointed out that the A fragment of the amyloid precursor protein found in plaques associated with $\mathrm{AD}$ increases the excitotoxicity associated with this pathway.

On the other hand, the anti-thrombotic activity of PGs may be important for protection against AD. For example, de la Torre (98) has hypothesized that $\mathrm{AD}$ is caused by the development of tortuous and flowimpeded capillaries in the brain. This would presumably promote intravascular coagulation, leading to ischemic damage in the brain that could promote the development of AD. It seems likely that clinical trials of COX-2 specific NSAIDs will be started before a role of COX-2 in AD is proved, but the mechanistic studies already under way will provide insight and direction for further developments.

\section{Cancer}

Several population-based studies have detected a 40 $50 \%$ decrease in relative risk for colorectal cancer in persons who regularly use aspirin and other NSAIDs (99-103). Clinical trials with NSAIDs in patients with Familial Adenomatous Polyposis have clearly demonstrated that NSAID treatment caused regression of preexisting adenomas (104). Studies in a variety of animal models (both genetic and carcinogen-induced) of colon cancer have also indicated a significant reduction in tumor multiplicity by NSAID treatment (105). In fact, some of these studies have shown as much as a 80 $90 \%$ reduction in tumor burden (106).
Initial attempts to determine the molecular basis for these observations found that both human and animal colorectal tumors express high levels of COX2 , whereas the normal intestinal mucosa has low to undetectable COX-2 expression (13, 107-109). These findings led to the hypothesis that COX-2 may be playing a role in colon cancer growth and progression. Subsequent experiments appear to support this view. For example, the effects of a highly selective COX-2 inhibitor (SC-58125) was tested on two different cell lines, only one of which has a high level of COX-2 expression and activity. It was observed that the inhibitor decreased cell growth in both in vitro and in vivo assays only in the COX-2-expressing cell line $(110-111)$. Other work in cell culture models has shown that COX-2 expression contributes significantly to the tumorigenic potential of epithelial cells by increasing adhesion to extracellular matrix and making them resistant to apoptosis (112). These phenotypic changes were shown to be reversible by treatment with a highly selective COX-2 inhibitor (106). Very recent work indicates that cyclooxygenase may play a vital role in the regulation of angiogenesis associated with neoplastic tumor cells (113). Hence, COX inhibitors may block the growth of blood vessels into developing tumors.

Genetic evidence supporting a role for COX-2 in the development of intestinal neoplasia has also been reported. Oshima et al. (114) assessed the development of intestinal adenomas in $\mathrm{Apc}^{\Delta 716}$ mice (a model in which a targeted truncation deletion in the tumor suppresser gene APC causes intestinal polyposis) in a wild-type and homozygous null COX-2 genetic background. The number and size of polyps were reduced dramatically (six- to eightfold) in the COX-2 null mice compared with COX-2 wild-type mice. In addition, treatment of the $\mathrm{Apc}^{\Delta 716}$ mice with a novel COX-2 inhibitor, Merck Frosst tricyclic, reduced polyp number more significantly than the non-selective NSAID, sulindac (114).

Whether NSAIDs block tumor progression solely by blocking PG synthesis is a matter still being debated. Several studies have shown that NSAIDs can act through mechanisms that are independent of their ability to inhibit COX (115-117). Most of this work has been done in cell culture models where effects are only seen at fairly high concentrations of drug (200-1000 $\mu \mathrm{M})$. Recently, animal studies have been reported that demonstrate the ability of sulindac sulfone to have protective effects against mammary tumors (116). Sulindac sulfone is a metabolite of the NSAID sulindac, which lacks the ability to inhibit COX directly. Therefore, some evidence indicates that COX-independent pathways also play an important role in the cancer chemopreventive properties of NSAIDs, and it is likely that both COX-dependent and -independent pathways are involved. 


\section{CONCLUSION}

This discussion highlights the many physiological systems in which the COX enzymes play functional roles. The precise mechanisms by which this biosynthetic pathway can mediate such diverse functions is largely unknown and will likely remain so until researchers can more fully characterize the biology of the various PG synthases and receptors downstream of COX. Nevertheless, identifying an inducible COX was a major breakthrough in this area. What evolved from this discovery was a paradigm in which one isoform, COX-1, was mainly responsible for the biosynthesis of PGs involved in homeostatic regulation, while the second isoform, COX-2, was primarily involved in producing PGs in response to a wide spectrum of environmental insults and internal stimuli. Such a mechanism appears to explain, at least in part, both the therapeutic and toxic effects of NSAIDs in humans. The major side effects of NSAIDs, gastroduodenal erosion and disruption of normal renal function, appear to caused by the inhibition of COX1 , while the antiinflammatory and analgesic activity of these drugs rests largely on their ability to inhibit COX-2.

Investigations into the role of COX-2 in disease have suggested that chronic activation of this enzyme may be pathological in the colon, where there is strong evidence to suggest that inhibition of COX-2 can limit the progression of colorectal cancer. Thus, a little more than a century after the discovery of aspirin, the potential clinical indications for NSAID use appear to be widening from their original purpose as analgesic agents. Ongoing studies to more clearly delineate the role of each COX isoform in both health and disease will be crucial in defining the use of these drugs in the next century.

We would like to acknowledge S.K. Dey, J. Richards, W. Stenson, R. Harris, and C. Pilbeam for their comments. We also thank C. Patrono, G. Fitzgerald, B. Shattuck-Brandt, and C. Williams for helpful suggestions. Much of the background for this review came together as a result of the 1st International Workshop on Cyclooxygenase-2, which was held in New Orleans, La., September 13-14, 1997. R.N. DuBois is the Mina Cobb Wallace Professor of Gastroeterology and Cancer Prevention.

\section{REFERENCES}

1. Vane, J. R. (1971) Inhibition of prostaglandin synthesis as a mechanism of action for aspirin-like drugs. Nature (London) 231, 232-235

2. Mead, J. F., Alfin-Slater, R. B., Howton, D. R., and Popjak, G. (1986) Prostaglandins, thromboxanes, and prostacyclin. In Lipids: Chemistry, Biochemistry, and Nutrition (Mead, J. F., ed) pp. 149-216, Plenum Press, New York

3. Herschman, H. R. (1996) Prostaglandin synthase 2. Biochim. Biophys. Acta 1299, 125-140
4. Herschman, H. R., Xie, W., and Reddy, S. (1995) Inflammation, reproduction, cancer and all that.... The regulation and role of the inducible prostaglandin synthase. Bioessays 17, 1031-1037

5. Simon, L. S. (1996) Actions and toxicity of nonsteroidal antiinflammatory drugs. Curr. Opin. Rheum. 8, 169-175

6. Breyer, M. D., Jacobson, H. R., and Breyer, R. M. (1996) Functional and molecular aspects of renal prostaglandin receptors. J. Am. Soc. Nephrol. 7, 8-17

7. Forman, B. M., Chen, J., and Evans, R. M. (1996) The peroxisome proliferator-activated receptors: ligands and activators. Ann. N.Y. Acad. Sci. 804, 266-275

8. Davies, N. M. (1995) Toxicity of nonsteroidal anti-inflammatory drugs in the large intestine. Diseases of the Colon $\mathcal{E}$ Rectum 38, 1311-1321

9. Murray, M. D., and Brater, D. C. (1993) Renal toxicity of the nonsteroidal anti-inflammatory drugs. Annu. Rev. Pharm. Toxicol. 32, 435-465

10. Raz, A., Wyche, A., Siegel, N., and Needleman, P. (1988) Regulation of fibroblast cyclooxygenase synthesis by interleukin-1. J. Biol. Chem. 263, 3022-3028

11. Reed, D. W., Bradshaw, W. S., Xie, W., and Simmons, D. L. (1996) In vivo and in vitro expression of a non-mammalian cyclooxygenase-1. Prostaglandins 52, 269-284

12. Smith, W., Garavito, R., and DeWitt, D. (1996) Prostaglandin endoperoxide $\mathrm{H}$ synthases (cyclooxygenases)-1 and -2. J. Biol. Chem. 271, 33157-33160

13. Kutchera, W., Jones, D. A., Matsunami, N., Groden, J., McIntyre, T. M., Zimmerman, G. A., White, R. L., and Prescott, S. M. (1996) Prostaglandin H synthase-2 is expressed abnormally in human colon cancer: evidence for a transcriptional effect. Proc. Natl. Acad. Sci. USA 93, 4816-4820

14. Reddy, S. T., and Herschman, H. R. (1996) Transcellular prostaglandin production following mast cell activation is mediated by proximal secretory phospholipase $\mathrm{A}_{2}$ and distal prostaglandin synthase 1. J. Biol. Chem. 271, 186-191

15. Williams, C. S., and DuBois, R. (1996) Prostaglandin endoperoxide synthase: why two isoforms? Am. J. Physiol. 270, G393G400

16. Hoff, T., DeWitt, D., Kaever, V., Resch, K., and GoppeltStruebe, M. (1993) Differentiation-associated expression of prostaglandin G/H synthase in monocytic cells. FEBS Lett. 320, $38-42$

17. Murakami, M., Matsumoto, R., Austen, K. F., and Arm, J. P. (1994) Prostaglandin endoperoxide synthase-1 and -2 couple to different transmembrane stimuli to generate prostaglandin D2 in mouse bone marrow-derived mast cells. J. Biol. Chem. 269, 22269-22275

18. Ueda, N., Yamashita, R., Yamamoto, S., and Ishimura, K. (1997) Induction of cyclooxygenase-1 in a human megakaryoblastic cell line (CMK) differentiated by phorbol ester. Biochim. Biophys. Acta 1344, 103-110

19. Smith, C. J., Morrow, J. D., Roberts, L. J., and Marnett, L. J. (1993) Differentiation of monocytoid THP-1 cells with phorbol ester induces expression of prostaglandin endoperoxide synthase-1 (COX-1). Biochem. Biophys. Res. Commun. 192, 787-793

20. Crofford, L. J. (1997) COX-1 and COX-2 tissue expression: implications and predictions. J. Rheum. 24, 15-19

21. Schafer, A. I. (1995) Effects of nonsteroidal antiinflammatory drugs on platelet function and systemic hemostasis. J. Clin. Phar macol. 35, 209-219

22. Palmer, B. F., and Henrich, W. L. (1995) Clinical acute renal failure with nonsteroidal anti-inflammatory drugs. Semin. Nephrol. 15, 214-227

23. Zambraski, E. J. (1995) The effects of nonsteroidal anti-inflammatory drugs on renal function: experimental studies in animals. Semin. Nephrol. 15, 205-213

24. Trevethick, M. A., Oakley, I., Clayton, N. M., and Strong, P. (1995) Non-steroidal anti-inflammatory drug-induced gastric damage in experimental animals: underlying pathological mechanisms. Gen. Pharmacol. 26, 1455-1459

25. Wallace, J. L. (1997) Nonsteroidal anti-inflammatory drugs and gastroenteropathy: the second hundred years. Gastroenterology 112, 1000-1016

26. Spangler, R. S. (1996) Cyclooxygenase 1 and 2 in rheumatic disease: implications for nonsteroidal anti-inflammatory drug therapy. Semin. Arth. Rheum. 26, 435-436 
27. DeWitt, D. L., Meade, E. A., and Smith, W. L. (1993) PGH synthase isoenzyme selectivity: the potential for safer nonsteroidal antiinflammatory drugs. Am. J. Med. 95, 40S-44S

28. Harris, R. C., McKanna, J. A., Akai, Y., Jacobson, H. R., DuBois, R. N., and Breyer, M. D. (1994) Cyclooxygenase-2 is associated with the macula densa in rat kidney and increases with salt restriction. J. Clin. Invest. 94, 2504-2510

29. Guan, Y., Chang, M., Cho, W., Zhang, Y., Redha, R., Davis, L., Chang, S., DuBois, R. N., Hao, C. M., and Breyer, M. (1997) Cloning, expression, and regulation of rabbit cyclooxygenase2 in renal medullary interstitial cells. Am. J. Physiol. 273, F18F26

30. Harris, R. C. (1996) The macula densa: recent developments. J. Hypertension 14, 815-822

31. Stokes, J. B. (1979) Effect of prostaglandin E2 on chloride transport across the rabbit thick ascending limb of Henle. $J$. Clin. Invest. 64, 495-502

32. Dinchuk, J. E., Car, B. D., Focht, R. J., Johnston, J. J., Jaffee, B. D., Covington, M. B., Contel, N. R., Eng, V. M., Collins, R. J., Czerniak, P. M., Gorry, S. A., and Trzaskos, J. M. (1995) Renal abnormalities and an altered inflammatory response in mice lacking cyclooxygenase II. Nature (London) 378, 406-409

33. Morham, S. G., Langenbach, R., Loftin, C. D., Tiano, H. F., Vouloumanos, N., Jennette, J. C., Mahler, J. F., Kluckman, K. D., Ledford, A., Lee, C. A., and Smithies, O. (1995) Prostaglandin synthase-2 gene disruption causes severe renal pathology in the mouse. Cell 83, 473-482

34. Cao, C., Matsumura, K., Yamagata, K., and Watanabe, Y. (1997) Involvement of cyclooxygenase-2 in LPS-induced fever and regulation of its mRNA by LPS in the rat brain. Am. J. Physiol. 272, R1712-R1725

35. Matsumura, K., Cao, C., and Watanabe, Y. (1997) Possible role of cyclooxygenase-2 in the brain vasculature in febrile response. Ann. N.Y. Acad. Sci. 813, 302-306

36. Taniguchi, Y., Yokoyama, K., Inui, K., Deguchi, Y., Furukawa, K., and Noda, K. (1997) Inhibition of brain cyclooxygenase-2 activity and the antipyretic action of nimesulide. Eur. J. Pharmacol. 330, 221-229

37. Cao, C., Matsumura, K., and Watanabe, Y. (1997) Induction of cyclooxygenase-2 in the brain by cytokines. Ann. N.Y. Acad. Sci. 813, 307-309

38. Bauer, M. K., Lieb, K., Schulze-Osthoff, K., Berger, M., GebickeHaerter, P. J., Bauer, J., and Fiebich, B. L. (1997) Expression and regulation of cyclooxygenase-2 in rat microglia. Eur. $J$. Biochem. 243, 726-731

39. Kaufmann, W. E., Worley, P. F., Taylor, C. V., Bremer, M., and Isakson, P. C. (1997) Cyclooxygenase-2 expression during rat neocortical development and in Rett syndrome. Brain Dev. 19, $25-34$

40. Yamagata, K., Andreasson, K., Kaufmann, W., Barnes, C., and Worley, P. (1993) Expression of a mitogen-inducible cyclooxygenase in brain neurons: regulation by synaptic activity and glucocorticoids. Neuron 11, 371-386

41. Kaufmann, W. E., Worley, P. F., Pegg, J., Bremer, M., and Isakson, P. (1996) COX-2, a synaptically induced enzyme, is expressed by excitatory neurons at postsynaptic sites in rat cerebral cortex. Proc. Natl. Acad. Sci. USA 93, 2317-2321

42. Tocco, G., Freire-Moar, J., Schreiber, S., Sakhi, S., Aisen, P., and Pasinetti, G. (1997) Maturational regulation and regional induction of cyclooxygenase-2 in rat brain: implications for Alzheimer's disease. Exp. Neurol. 144, 339-349

43. Miettinen, S., Fusco, F. R., Yrjanheikki, J., Keinanen, R., Hirvonen, T., Roivainen, R., Narhi, M., Hokfelt, T., and Koistinaho, J. (1997) Spreading depression and focal brain ischemia induce cyclooxygenase-2 in cortical neurons through N-methyl-D-aspartic acid-receptors and phospholipase A2. Proc. Natl. Acad. Sci. USA 94, 6500-6505

44. Scheiman, J. M. (1996) NSAIDs, gastrointestinal injury, and cytoprotection. Gastroenterol. Clin. N. Am. 25, 279-298

45. Roth, S. H. (1996) NSAID gastropathy. A new understanding. Arch. Int. Med. 156, 1623-1628

46. Cohn, S. M., Schloemann, S., Tessner, T., Seibert, K., and Stenson, W. F. (1997) Crypt stem cell survival in the mouse intestinal epithelium is regulated by prostaglandins synthesized through cyclooxygenase-1. J. Clin. Invest. 99, 1367-1379

47. Eckmann, L., Stenson, W. F., Savidge, T. C., Lowe, D. C., Barrett, K. E., Fierer, J., Smith, J. R., and Kagnoff, M. F. (1997)
Role of intestinal epithelial cells in the host secretory response to infection by invasive bacteria: bacterial entry induces epithelial prostaglandin $\mathrm{H}$ synthase-2 expression and prostaglandin $\mathrm{E}_{2}$ and $\mathrm{F}_{2 \alpha}$ production. J. Clin. Invest. 100, 296-309

48. Simon, L. S. (1997) Biologic effects of nonsteroidal anti-inflammatory drugs. Curr. Opin. Rheum. 9, 178-182

49. Giannella, R. A., Formal, S. B., Dammin, G. J., and Collins, H (1973) Pathogenesis of Salmonellosis. Studies of fluid secretion, mucosal invasion, and morphologic reactions in the rabbit ileum. J. Clin. Invest. 52, 441-453

50. O'Brien, W. F. (1995) The role of prostaglandins in labor and delivery. Clin. Perinatol. 22, 973-984

51. Zuckerman, H., Reiss, U., and Rubinstein, I. (1974) Inhibition of human premature labor by indomethacin. Obstet. Gynecol. 44, 787-792

52. Hammerman, C. (1995) Patent ductus arteriosus. Clinical relevance of prostaglandins and prostaglandin inhibitors in PDA pathophysiology and treatment. Clin. Perinatol. 22, 457-479

53. Richards, J. S., Fitzpatrick, S. L., Clemens, J. W., Morris, J. K., Alliston, T., and Sirois, J. (1995) Ovarian cell differentiation: a cascade of multiple hormones, cellular signals, and regulated genes. Rec. Prog. Hormone Res. 50, 223-254

54. Richards, J. (1994) Hormonal control of gene expression in the ovary. Endocr. Rev. 15, 725-751

55. Tsafriri, A. (1995) Ovulation as a tissue remodelling process. Proteolysis and cumulus expansion. Adv. Exp. Med. Biol. 377, $121-140$

56. Li, J., Simmons, D. L., and Tsang, B. K. (1996) Regulation of hen granulosa cell prostaglandin production by transforming growth factors during follicular development: involvement of cyclooxygenase-2. Endocrinology 137, 2522-2529

57. Narko, K., Ritvos, O., and Ristimaki, A. (1997) Induction of cyclooxygenase- 2 and prostaglandin $\mathrm{F}_{2 \mathrm{a}}$ receptor expression by interleukin-1b in cultured human granulosa-luteal cells. Endocrinology 138, 3638-3644

58. Morris, J. K., and Richards, J. S. (1996) An E-box region within the prostaglandin endoperoxide synthase-2 (PGS-2) promoter is required for transcription in rat ovarian granulosa cells. $J$. Biol. Chem. 271, 16633-16643

59. Chakraborty, I., Das, S. K., Wang, J., and Dey, S. K. (1996) Developmental expression of the cyclooxygenase-1 and cyclooxygenase- 2 genes in the peri-implantation mouse uterus and their differential regulation by the blastocyst and ovarian steroids. $J$. Mol. Endocrinol. 16, 107-122

60. Yang, Z. M., Das, S. K., Wang, J., Sugimoto, Y., Ichikawa, A., and Dey, S. K. (1997) Potential sites of prostaglandin actions in the periimplantation mouse uterus: differential expression and regulation of prostaglandin receptor genes. Biol. Reprod. 56, 368-379

61. Lim, H., and Dey, S. K. (1997) Prostaglandin E-2 receptor subtype EP2 gene expression in the mouse uterus coincides with differentiation of the luminal epithelium for implantation. Endocrinology 138, 4599-4606

62. Lim, H., Paria, B. C., Das, S. K., Dinchuk, J. E., Langenbach, R., Trzaskos, J. M., and Dey, S. K. (1997) Multiple female reproductive failures in cyclooxygenase-2 deficient mice. Cell 91, 197-208

63. Sugimoto, Y., Yamasaki, A., Segi, E., Tsuboi, K., Aze, Y., Nishimura, T., Oida, H., Yoshida, N., Ranaka, R., Karsuyama, M. Hasumoto, K., Murata, T., Hirata, M., Ushikubi, F., Negishi, M., Ichikawa, A., and Narumiya, S. (1997) Failure of parturition in mice lacking the prostaglandin F receptor. Science 277, 681-683

64. Kawaguchi, H., Pilbeam, C. C., Harrison, J. R., and Raisz, L. G. (1995) The role of prostaglandins in the regulation of bone metabolism. Clin. Orthop. Relat. Res. 313, 36-46

65. Woodiel, F. N., Fall, P. M., and Raisz, L. G. (1996) Anabolic effects of prostaglandins in cultured fetal rat calvariae: structure-activity relations and signal transduction pathway. $J$. Bone Miner. Res. 11, 1249-1255

66. Klein-Nulend, J., Burger, E. H., Semeins, C. M., Raisz, L. G., and Pilbeam, C. C. (1997) Pulsating fluid flow stimulates prostaglandin release and inducible prostaglandin $\mathrm{G} / \mathrm{H}$ synthase mRNA expression in primary mouse bone cells. J. Bone Miner. Res. 12, 45-51

67. Pilbeam, C. C., Harrison, J. R., and Raisz, L. G. (1996) Prostaglandins and bone metabolism. In Principles of Bone Biology (Bi- 
lezikian, J., Raisz, L. and Rodan, G., eds.), pp. 715-728, Academic Press, New York

68. Pilbeam, C. C., Fall, P. M., Alander, C. B., and Raisz, L. G. (1997) Differential effects of nonsteroidal anti-inflammatory drugs on constituitive and inducible prostaglandin G/ $\mathrm{H}$ synthase in cultured bone cells. J. Bone Miner. Res. 12, 1198-1203

69. Allison, A. C., Chin, R. C., and Cheng, Y. (1993) Cyclooxygenase inhibitors vary widely in potency for preventing cytokineinduced bone resorption. Ann. N.Y. Acad. Sci. 696, 303-306

70. Jeffcoat, M. K., Reddy, M. S., Moreland, L. W., and Koopman, W.J. (1993) Effects of nonsteroidal antiinflammatory drugs on bone loss in chronic inflammatory disease. Ann. N.Y. Acad. Sci. 696, 292-302

71. Sato, T., Morita, I., Sakaguchi, K., Nakahama, K., and Murota, S. (1995) Involvement of cyclooxygenase- 2 in bone loss induced by interleukin-1 $\beta$. Adv. Prostaglandin, Thromboxane, Leukotriene Res. 23, 445-447

72. Tai, H., Miyaura, C., Pilbeam, C. C., Tamura, T., Ohsugi, Y., Koishihara, Y., Kubodera, N., Kawaguchi, H., Raisz, L. G., and Suda, T. (1997) Transcriptional induction of cyclooxygenase-2 in osteoblasts is involved in interleukin-6-induced osteoclast formation. Endocrinology 138, 2372-2379

73. Onoe, Y., Miyaura, C., Kaminakayashiki, T., Nagai, Y., Noguchi, K., Chen, Q. R., Seo, H., Ohta, H., Nozawa, S., Kudo, I., and Suda, T. (1996) IL-13 and IL-4 inhibit bone resorption by suppressing cyclooxygenase-2-dependent prostaglandin synthesis in osteoblasts. J. Immunol. 156, 758-764

74. Tetradis, S., Pilbeam, C. C., Liu, Y., Herschman, H. R., and Kream, B. E. (1997) Parathyroid hormone increases prostaglandin $\mathrm{G} / \mathrm{H}$ synthase-2 transcription by a cyclic adenosine $3^{\prime}, 5^{\prime}$-monophosphate-mediated pathway in murine osteoblastic MC3T3-E1 cells. Endocrinology 138, 3594-3600

75. Tjandrawinata, R. R., Vincent, V. L., and Hughes-Fulford, M. (1997) Vibrational force alters mRNA expression in osteoblasts. FASEB J. 11, 493-497

76. Lands, W. E. (1979) The biosynthesis and metabolism of prostaglandins. Annu. Rev. Physiol. 41, 633-652

77. Needleman, P., and Isakson, P. C. (1997) The discovery and function of COX-2. J. Rheum. 24, 6-8

78. Anderson, G. D., Hauser, S. D., McGarity, K. L., Bremer, M. E., Isakson, P. C., and Gregory, S. A. (1996) Selective inhibition of cylooxygenase (COX)-2 reverses inflammation and expression of COX-2 and interleuken 6 in rat adjuvant arthritis. J. Clin. Invest. 97, 2672-2679

79. Amin, A. R., Attur, M., Patel, R. N., Thakker, G. D., Marshall, P. J., Rediske, J., Stuchin, S. A., Patel, I. R., and Abramson, S. B. (1997) Superinduction of cyclooxygenase-2 activity in human osteoarthritis-affected cartilage: influence of nitric oxide. J. Clin. Invest. 99, 1231-1237

80. Kang, R. Y., Freire-Moar, J., Sigal, E., and Chu, C. Q. (1996) Expression of cyclooxygenase-2 in human and an animal model of rheumatoid arthritis. Br. J. Rheum. 35, 711-718

81. Manfield, L., Jang, D., and Murrell, G. A. (1996) Nitric oxide enhances cyclooxygenase activity in articular cartilage. Inflamm. Res. 45, 254-258

82. Penning, T., Talley, J., Bertenshaw, S., Carter, J., Collins, P., Docter, S., Graneto, M., Lee, L., Malecha, J., Miyashiro, J., Rogers, R., Rogier, D., Yu, S., Andersen, G., Burton, E., Cogburn, J., Gregory, S., Koboldt, C., Perkins, W., Seibert, K., Veenhuizen, A., Zhang, Y., and Isakson, P. (1997) Synthesis and biological evaluation of the 1,5-diarylpyrazole class of cyclooxygenase-2 inhibitors: identification of 4-[5-(4-methylphenyl)3-(trifluoromethyl)-1H-pyrazol-1-yl] benzenesulfonamide (SC58635, celecoxib).J. Med. Chem. 440, 1347-1365

83. Lipsky, P. E., and Isakson, P. C. (1997) Outcome of specific COX-2 inhibition in rheumatoid arthritis. J. Rheum. 24, 9-14

84. Dray, A., and Urban, L. (1996) New pharmacological strategies for pain relief. Annu. Rev. Pharmacol. Toxicol. 36, 253-280

85. Yamamoto, T., and Nozaki-Taguchi, N. (1996) Analysis of the effects of cyclooxygenase (COX)-1 and COX-2 in spinal nociceptive transmission using indomethacin, a non-selective COX inhibitor, and NS-398, a COX-2 selective inhibitor. Brain Res. 739, 104-110

86. Cherng, C. H., Wong, C. S., and Ho, S. T. (1996) Spinal actions of nonsteroidal anti-inflammatory drugs. Acta Anaesthesiol. Sinica 34, 81-88
87. Cashman, J. N., and McAnulty, G. (1995) Nonsteroidal antiinflammatory drugs in perisurgical pain management. Mechanisms of action and rationale for optimum use. Drugs 49, 51-70

88. Cashman, J. N. (1996) The mechanisms of action of NSAIDs in analgesia. Drugs 52, 13-23

89. Beiche, F., Scheuerer, S., Brune, K., Geisslinger, G., and Goppelt-Struebe, M. (1996) Up-regulation of cyclooxygenase-2 mRNA in the rat spinal cord following peripheral inflammation. FEBS Lett. 390, 165-169

90. Laird, J. M. A., Herrero, J. F., Garcia de la Rubia, P., and Cervero, F. (1997) Analgesic activity of the novel COX-2 preferring NSAID, meloxicam, in mono-arthritic rats: central and peripheral components. Inflamm. Res. 46, 203-210

91. Lane, N. E. (1997) Pain management in osteoarthritis: the role of COX-2 inhibitors. J. Rheum. 24, 20-24

92. Seibert, K., Zhang, Y., Leahy, K., Hauser, S., Masferrer, J., Perkins, W., Lee, L., and Isakson, P. (1994) Pharmacological and biomedical demonstration of the role of cyclooxygenase 2 in inflammation and pain. Proc. Natl. Acad. Sci. USA 91, 12013-12017

93. Andersen, K., Launer, L. J., Ott, A., Hoes, A. W., Breteler, M. M., and Hofman, A. (1995) Do nonsteroidal anti-inflammatory drugs decrease the risk for Alzheimer's disease? The Rotterdam Study. Neurology 45, 1441-1445

94. McGeer, P. L., Schulzer, M., and McGeer, E. G. (1996) Arthritis and anti-inflammatory agents as possible protective factors for Alzheimer's disease: a review of 17 epidemiologic studies. Neurology 47, 425-432

95. Stewart, W. F., Kawas, C., Corrada, M., and Metter, E. J. (1997) Risk of Alzheimer's disease and duration of NSAID use. Neurology 48, 626-632

96. Breitner, J., Welsh, K., Helms, M., Gaskell, P., Gau, B., Roses, A., Pericak-Vance, M., and Saunders, A. (1995) Delayed onset of Alzheimer's disease with nonsteroidal anti-inflammatory and histamine H2 blocking drugs. Neurobiol. Aging 16, 523-530

97. Breitner, J. (1996) NeurobiologInflammatory processes and antiinflammatory drugs in Alzheimer's disease: a current appraisal. Neurobiol. Aging 17, 789-794

98. de la Torre, J. C. (1997) Cerebromicrovascular pathology in Alzheimer's disease compared to normal aging. Gerontology 43 , 26-43

99. Giovannucci, E., Rimm, E. B., Stampfer, M. J., Colditz, G. A., Ascherio, A., and Willett, W. C. (1994) Aspirin use and the risk for colorectal cancer and adenoma in male health professionals. Ann. Int. Med. 121, 241-246

100. Giovannucci, E., Egan, K. M., Hunter, D. J., Stampfer, M. J., Colditz, G. A., Willett, W. C., and Speizer, F. E. (1995) Aspirin and the risk of colorectal cancer in women. N. Engl. J. Med.333, 609-614

101. Smalley, W., and DuBois, R. N. (1997) Colorectal cancer and non steroidal anti-inflammatory drugs. Adv. Pharmacol. $\mathbf{3 9}$ $1-20$

102. Thun, M. J., Namboodiri, M. M., and Heath, C. W. J. (1991) Aspirin use and reduced risk of fatal colon cancer. N. Engl. J. Med. 325, 1593-1596

103. Thun, M. J., Namboodiri, M. M., Calle, E. E., Flanders, W. D., and Heath, C. W. J. (1993) Aspirin use and risk of fatal cancer. Cancer Res. 53, 1322-1327

104. Giardiello, F. M., Offerhaus, G. J. A., and DuBois, R. N. (1995) The role of nonsteroidal antiinflammatory drugs in colorectal cancer prevention. Eur. J. Cancer 31A, 1071-1076

105. Williams, C. S., Smalley, W., and DuBois, R. N. (1997) Aspirin use and potential mechanisms for colorectal cancer prevention. J. Clin. Invest. 100, 1-5

106. Kawamori, T., Rao, C. V., Seibert, K., and Reddy, B. S. (1998) Chemopreventive activity of celecoxib, a specific cyclooxygenase-2 inhibitor, against colon carcinogenesis. Cancer Res. 58, 409-412

107. Eberhart, C. E., Coffey, R. J., Radhika, A., Giardiello, F. M., Ferrenbach, S., and DuBois, R. N. (1994) Up-regulation of cyclooxygenase 2 gene expression in human colorectal adenomas and adenocarcinomas. Gastroenterology 107, 1183-1188

108. Kargman, S., O’Neill, G., Vickers, P., Evans, J., Mancini, J., and Jothy, S. (1995) Expression of prostaglandin G/H synthase-1 and -2 protein in human colon cancer. Cancer Res. 55, 25562559

109. Sano, H., Kawahito, Y., Wilder, R. L., Hashiramoto, A., Mukai, S., Asai, K., Kimura, S., Kato, H., Kondo, M., and Hla, T. (1995) 
Expression of cyclooxygenase-1 and -2 in human colorectal cancer. Cancer Res. 55, 3785-3789

110. Sheng, H., Shao, J., Kirkland, S. C., Isakson, P., Coffey, R., Morrow, J., Beauchamp, R. D., and DuBois, R. N. (1997) Inhibition of human colon cancer cell growth by selective inhibition of cyclooxygenase-2. J. Clin. Invest. 99, 2254-2259

111. Sheng, H., Shao, J., Morrow, J., Beauchamp, R. D., and DuBois, R. N. (1998) Modulation of apoptosis by prostaglandin treatment in human colon cancer cells. Cancer Res. 58, 362-366

112. Tsujii, M., and DuBois, R. N. (1995) Alterations in cellular adhesion and apoptosis in epithelial cells overexpressing prostaglandin endoperoxide synthase-2. Cell 83, 493-501

113. Tsujii, M., Kawano, S., Tsuji, S., Sawaoka, H., Hori, M., and DuBois, R. N. (1998) Cyclooxygenase regulates angiogenesis induced by colon cancer cells. Cell 93, 705-716

114. Oshima, M., Dinchuk, J. E., Kargman, S. L., Oshima, H., Hancock, B., Kwong, E., Trzaskos, J. M., Evans, J. F., and Taketo,
M. M. (1996) Suppression of intestinal polyposis in $\mathrm{APC}^{\Delta 716}$ knockout mice by inhibition of prostaglandin endoperoxide synthase-2 (COX-2). Cell 87, 803-809

115. Piazza, G. A., Rahm, A. L., Krutzsch, M., Sperl, G., Paranka, N. S., Gross, P. H., Brendel, K., Burt, R. W., Alberts, D. S., Pamukcu, R., and Ahnen, D. J. (1995) Antineoplastic drugs sulindac sulfide and sulfone inhibit cell growth by inducing apoptosis. Cancer Res. 55, 3110-3116

116. Thompson, H. J., Jiang, C., Lu, J. X., Mehta, R. G., Piazza, G. A., Paranka, N. S., Pamukcu, R., and Ahnen, D. J. (1997) Sulfone metabolite of sulindac inhibits mammary carcinogenesis. Cancer Res. 57, 267-271

117. Hanif, R., Pittas, A., Feng, Y., Koutsos, M. I., Qiao, L., Staiano-Coico, L., Shiff, S. I., and Rigas, B. (1996) Effects of nonsteroidal antiinflammatory drugs on proliferation and on induction of apoptosis in colon cancer cells by a prostaglandin-independent pathway. Biochem. Pharmacol. 52, 237-245 